\title{
O ENSINO DA HISTÓRIA E CULTURA AFRO-BRASILEIRA E INDÍGENA NO CURRÍCULO DOS CURSOS DE PEDAGOGIA DE DUAS INSTITUIÇÕES DE ENSINO SUPERIOR
}

\author{
THE TEACHING OF AFRO-BRAZILIAN AND INDIGENOUS \\ HISTORY AND CULTURE IN THE CURRICULUM OF THE \\ PEDAGOGY COURSES OF TWO HIGHER EDUCATION \\ INSTITUTIONS
}

\author{
Danielle Pereira de Araújo \\ Universidade de Coimbra \\ Marcos Antônio Batista da Silva \\ Universidade de Coimbra
}

\section{RESUMO}

Este artigo analisa a introdução do ensino da História e Cultura Afro-brasileira e Indígena nos projetos político-pedagógicos e nos currículos dos cursos de Pedagogia da Universidade Federal do Rio de Janeiro (UFRJ) e da Universidade da Integração Internacional da Lusofonia Afro-Brasileira (UNILAB). A investigação está ancorada no debate realizado pelas ciências sociais no campo da educação para as relações étnico-raciais, à luz das Diretrizes Curriculares Nacionais para a Educação das Relações ÉtnicoRaciais e para o Ensino de História e Cultura Afro-Brasileira e Africana. O método de investigação incluiu a análise dos projetos pedagógicos, currículos e entrevistas com discentes e docentes das duas Instituições. A pesquisa revela as disputas e ambiguidades existentes na construção da educação antirracista nos cursos de pedagogia, onde o currículo expressa as tensões, contradições e interesses de grupos que estão dentro e fora da universidade.

Palavras-chaves: relações étnico-raciais; ensino superior; descolonização curricular, antirracismo.

\begin{abstract}
This article analyses the introduction of Afro-Brazilian and Indigenous History and Culture teaching in the political-pedagogical projects and curricula of the Pedagogy courses of the Federal University of Rio de Janeiro (UFRJ) and the University of International Integration of the Afro-Brazilian Lusophony (UNILAB). The research is anchored in the debate held by the social sciences in the field of education for ethnic-racial relations, in the light of the National Curricular Guidelines for the Education of EthnicRacial Relations and for the Teaching of Afro-Brazilian and African History and Culture. The research
\end{abstract}


method included the analysis of pedagogical projects, curricula and interviews with students and teachers from both institutions. The research reveals the disputes and ambiguities that exist in the construction of antirracist education in pedagogical courses, where the curriculum expresses the tensions, contradictions and interests of groups that are inside and outside the university.

Keywords: ethnic-racial relations; higher education; decolonization curriculum, antirracism. 


\section{INTRODUÇÃO}

O presente $\operatorname{artigo}^{1}$ analisa os currículos do curso de Pedagogia da Universidade Federal do Rio de Janeiro (UFRJ) e da Universidade da Integração Internacional da Lusofonia Afro-Brasileira (UNILAB) à luz das "Diretrizes Curriculares Nacionais para a Educação das Relações Étnico-Raciais e para o Ensino de História e Cultura AfroBrasileira e Africana” (BRASIL, 2004) 2 ${ }^{2}$ Essas Diretrizes (DCN), circunscritas na Lei 10.639/2003, 3 (BRASIL, 2003) oferecem coordenadas que assinalam que " as Instituições de Ensino Superior incluirão nos conteúdos de disciplinas e atividades curriculares dos cursos que ministram, a Educação das Relações Étnico-Raciais (BRASIL, 2004, p.31).

Nilma Gomes (2012) sublinha que em decorrência da introdução obrigatória do ensino da História e Cultura Afro-brasileira e Africana nos currículos do sistema educacional no Brasil, é necessária:

[...] mudança de práticas e descolonização dos currículos da educação básica e superior[...]. Mudanças de representação e de práticas. Exige questionamento dos lugares de poder. Indaga a relação entre direitos e privilégios arraigada em nossa cultura política e educacional, em nossas escolas e na própria universidade (p.100).

De modo geral, entendemos que as DCN apontam para a importância de as instituições educacionais apoiarem os docentes na elaboração de planos políticopedagógicos e curriculares, cujo cerne seja a possibilidade de construção articulada e integrada de práticas de ensino antirracista. Nesse sentido, perguntamos: como os

\footnotetext{
${ }^{1}$ Este artigo foi realizado no âmbito projeto POLITICS - A política de (anti)racismo na Europa e na América Latina: produção de conhecimento, decisão política e lutas coletivas (Projeto 725402 POLITICS - ERC-2016-COG), junto ao Centro de Estudos Sociais, Universidade de Coimbra.

2 BRASIL. Conselho Nacional de Educação. Conselho Pleno. Parecer CNE/CP 003/2004. Diretrizes Curriculares para a Educação das Relações Étnico-Raciais e para o Ensino de História e Cultura AfroBrasileira e Africana. Brasília, DF: Ministério da Educação, 2004.

3 BRASIL. Lei ${ }^{0}$ 10.639, de 9 de janeiro de 2003. Altera a Lei no 9.394, de 20 de dezembro de 1996, que estabelece as diretrizes e bases da educação nacional, para incluir no currículo oficial da Rede de Ensino a obrigatoriedade da temática "História e Cultura Afro-Brasileira", e dá outras providências. Brasília, $\mathrm{DF}, 2003$.
} 
cursos de pedagogia estão implementando, em seus planos político-pedagógicos e curriculares, a perspetiva da educação das relações étnico-raciais? Quais são os princípios, categorias e conceitos-chaves que têm composto o currículo e as diretivas normativas quanto ao tema?

O referencial teórico-metodológico deste artigo dialoga com a teoria crítica de raça e racismo (QUIJANO, 2005; HALL, 2003; GOMES, 2012), assim como dos estudos sobre educação e currículo (FREIRE, 2005; REGIS e BASILIO, 2018; YOUNG, 2014), e da análise crítica do discurso (van Dijk, 1993). A metodologia está baseada na investigação de documentos públicos (planos políticos-pedagógicos) complementada por entrevistas realizadas nas duas universidades (2019-2020).

O artigo está dividido em 6 seções. A primeira seção, apresenta alguns estudos recentes sobre o debate em torno do antirracismo e currículo no contexto brasileiro. $\mathrm{Na}$ segunda e terceira seções, apresentamos algumas análises acerca do currículo e do projeto pedagógico do curso de pedagogia da UFRJ. Na quarta e quinta seções, fazemos algumas reflexões em torno do contexto político e histórico que leva à criação da UNILAB e o projeto político pedagógico e curricular do curso de pedagogia e finalizamos com as considerações finais.

\section{Currículo, educação antirracista e ensino superior brasileiro}

Desde os anos 70 registramos os primeiros trabalhos acadêmicos voltados à discussão sobre as desigualdades de raça e a sua reprodução no ambiente educacional, entretanto será a partir dos anos 2000 que teremos uma produção mais sistemática e perene acerca da relação potente entre currículo e educação antirracista. Diversos autores têm investigado este tema, como pudemos observar nos estudos de Carvalho e Castro (2017), Chagas (2017), Coelho e Coelho, 2018, Passos e Santos (2018), Ferreira (2018), Régis e Basílio (2018). Para este artigo, privilegiamos algumas discussões apresentadas nos estudos de Ferreira (2018) e Regis e Basílio (2018), por estarem mais próximos ao debate proposto neste artigo. 
Ferreira (2018) investigou de que forma a questão racial é discutida nos currículos de algumas universidades públicas no estado do Rio de Janeiro, em particular no curso de Pedagogia. As análises da autora nos revelam conflitos para a inclusão de conteúdo no currículo "de uma forma que fomente a intersecção entre disciplinas nos cursos analisados, de modo a tornar mais consistente a sua abordagem" (p.13). Autora cita ainda outros componentes que se apresentaram como dificuldades para a introdução do debate nos cursos de Pedagogia investigados:

[...] as políticas de corte de investimentos na educação pública, que [tinham acarretado] a diminuição de concursos públicos específicos para docentes que conduzirão essa discussão; as dificuldades para tratar da religiosidade africana e afro-brasileira junto aos estudantes de Pedagogia; [...], dentre outros aspectos (FERREIRA, p.13, grifo nosso).

Apreendemos com Ferreira (2018) que é crucial uma mudança profunda na estrutura curricular das universidades, assim como um maior engajamento do corpo docente com a questão racial.

Régis e Basílio (2018) realizaram um trabalho exaustivo de sistematização e análise de artigos, teses e dissertações sobre a produção analítica em torno da discussão sobre currículo e relações étnico-raciais, entretanto, como concluem os referidos autores "[...] a maior parte dos trabalhos apresenta resultados de pesquisas e de práticas curriculares realizadas nas instituições da educação básica” (p. 41), deixando assim uma tarefa ainda por fazer que é a análise dos impactos da Lei 10.639/2003 no ensino superior. Assim, os autores assinalam que, das 101 pesquisas produzidas entre 2003 e 2014, apenas 18 trabalhos se debruçaram sobre educação antirracista nas práticas curriculares em universidades.

A análise das discussões levantadas pelos trabalhos investigados pelos autores acerca de 101 pesquisas produzidas entre 2003 e 2014, nos revelam os entraves na produção do saber na academia brasileira no que tange à discussão sobre práticas curriculares antirracistas no ensino superior.

Observamos que, ao longo de mais de uma década, as reflexões em torno do currículo no ensino superior e da introdução do ensino da História e Cultura Africana e Afro-Brasileira parecem não ter conseguido ainda se estabelecer enquanto linha de 
pesquisa no campo dos estudos sobre currículo. Apesar de ter produzido "ruído" no campo das discussões sobre currículo antirracista e educação superior, o volume de estudos nessa área é quatro vezes menor do que os trabalhos sobre as experiências curriculares antirracistas no ensino básico.

Reconhecemos que uma das razões para a persistência do maior número de estudos sobre a aplicação da lei no ensino básico talvez possa estar relacionada com o fato da Lei 10.639/o3 ter tornado obrigatória o ensino da História e Cultura Afrobrasileira voltadas para este âmbito de ensino, "deixando de fora o ensino superior". Em nossa leitura, isso explicaria, apenas em parte, a baixa produção acadêmica acerca do debate sobre currículo universitário e ensino de História e Cultura Afro-Brasileira já que nas DCN constam normativas para a implementação da referida Lei também para o ensino superior. Entendemos que a escassez evidencia o comprometimento de grande parte da academia com os paradigmas eurocêntricos dominantes no modo de (não) discutir relações étnico-raciais.

Juntamente com Gomes (2012), partimos do entendimento de que o debate sobre práticas curriculares antirracistas não pode limitar-se à inclusão de disciplinas sobre "diversidade", "multiculturalismo" ou "inclusão". E com isso não estamos desconsiderando a luta, os enfrentamentos e as negociações (necessárias) feitas por professores, militantes, e coletivos negros no interior dos cursos para a introdução de disciplinas nas matrizes curriculares, apenas chamamos atenção para o entendimento de que:

“[...] [a] questão pedagógica-curricular, por isso, é muito mais profunda e anterior ao mero rearranjo do conhecimento disciplinar: é de ordem epistemológica, pois vem da concepção de conhecimento e de ordem pedagógica, isto é, de como se percebe o ato de aprender" (CUNHA, 1998, p.15).

\section{A formação de pedagogos e o estudo das relações étnico-raciais na Faculdade de Educação da UFRJ}

A Faculdade de Educação do Centro de Filosofia e Ciências Humanas da UFRJ (FE/UFRJ) é uma unidade de ensino, pesquisa e extensão da UFRJ, e foi criada em 
1968, a partir da extinta Faculdade Nacional de Filosofia. (PPC/PEDAGOGIA /UFRJ, 2015). Para este texto, nossa análise situa-se no campo das relações étnico-raciais, em particular, no que tangencia o Plano Pedagógico de Curso (PPC) e o Currículo4 do Curso de Licenciatura em Pedagogia da FE/UFRJ. Ressaltamos que o escopo desse artigo não permite abarcar todos os tópicos que compõem o PPC/Currículo do curso de licenciatura em Pedagogia. Deste modo, a análise recaiu sobre o título das disciplinas que dialogavam com a nossa proposta (educação das relações étnicoraciais, e os processos de descolonização), localizados em quatro disciplinas, que serão explicitadas no decorrer deste trabalho.

É importante "anunciar a possibilidade de construção de uma Pedagogia Decolonial, relacionando-a à Educação da Relações Étnico-Raciais que substancie uma práxis curricular antirracista”, como evidenciam Ferreira e Silva (2018, p. 77). Para esses autores, o conceito de "Pedagogia Decolonial tem relação com as formulações e práticas educacionais presentes em Frantz Fanon e Paulo Freire” (ibidem, p.105), as quais ressaltam a liberação do poder colonizador, branco, europeu, (MAESO,2019) como pudemos observar em uma disciplina optativa do curso de Pedagogia “Colonialismo, Educação e Pedagogia da Revolução".

Focalizamos no PPC supracitado, que a depender das necessidades e interesses locais e regionais, no curso de Licenciatura em Pedagogia “poderão ser, especialmente, aprofundadas questões que devem estar presentes na formação de todos os educadores, relativas, entre outras, [...] a, educação étnico-racial; educação indígena; educação nos remanescentes de quilombos. (PPC/PEDAGOGIA/UFRJ, 2015. p.28).

Nas últimas décadas, na sociedade brasileira, o movimento negro - e nesse caso é importante ressaltarmos a contribuição das mulheres negras neste processo, que elegeram o acesso à educação como uma bandeira de emancipação política (ANDRADE, 2018) - tem interrogado o sistema educacional no país. Contudo, perguntamos: como o curso de Licenciatura em Pedagogia da UFRJ tem incluído em seu PPC a discussão sobre o ensino da História e Cultura Afro-brasileira e Indígena?

4 https://siga.ufrj.br/sira/temas/zire/frameConsultas.jsp?mainPage=/repositoriocurriculo/B137164D-92A4-F79F-3C28-DD379D8Bo991.html 
Nesta direção, tecemos algumas observações sobre alguns tópicos selecionados, primeiro, a "Sala de Leitura e Brinquedoteca: projeto de extensão felicidade clandestina”, que envolve uma BRINQUEDOTECA, visando à formação inicial e continuada de docentes para a atuação no ensino de linguagem desde a Educação Infantil até a Educação de Jovens e Adultos. (PPC/PEDAGOGIA/UFRJ, 2015. p.47). Neste sentido, nossa análise focou nas "Referências Bibliográficas" propostas e indicadas no projeto da Sala de Leitura (ibidem, p.55-58).

Deste modo localizamos que a maioria das obras e textos sugeridos são de autores brasileiros (80\%), mas não localizamos textos que faziam menção explícita em seus títulos à temática das relações étnico-raciais. Compreendemos que considerar a literatura que discuta e valorize o ensino da História e Cultura Afro-Brasileira e Indígena é primordial para a equidade racial, como consta das DCN, "a educação das relações étnico-raciais, [...], se desenvolverão no cotidiano das escolas, [...], na utilização de sala de leitura, biblioteca, brinquedoteca”. (BRASIL, 2004, p.21).

Segundo, no que tangencia ao "Espaço de Atendimento Psicopedagógico" (EAP), onde "serão tratadas as questões qualitativas de sua vida acadêmica" (PPC/FE/UFRJ, p.64, 2015), observamos que está relacionado com as mudanças recentemente implantadas no acesso à UFRJ:

\begin{abstract}
Com a adesão ao ENEM e a implantação de políticas de ações afirmativas, há uma necessidade crescente de ações que contribuam para a inserção dos alunos ingressantes na cultura acadêmica. [...]. Sabemos que muitas vezes surgem dificuldades nesse processo, as quais, caso não sejam sanadas, podem levar o aluno à evasão. São diversas as dificuldades enfrentadas pelos alunos nesse processo de adaptação, tanto em relação aos novos vínculos que devem ser constituídos por eles neste espaço quanto em relação à modificação de sua modalidade de aprendizagem e ensino (ibidem, p.64).
\end{abstract}

Notamos que, apesar do sugerido, não há um dado disponibilizado no Plano que de fato comprove que os ingressantes por políticas afirmativas e Exame Nacional do Ensino Médio (ENEM) tenham dificuldade de adaptação, de criação de novos vínculos e aprendizagem. Os documentos institucionais, no geral, discutem pouco sobre raça e antirracismo, mas quando abordam se detém a pensar sobre as possíveis "carências e 
fragilidades" dos cotistas. Neste contexto, o relato de um dos nossos entrevistados, professor universitário, revela que há uma mudança no perfil dos discentes:

\footnotetext{
Então, quando eu entrei aqui, como professor, com quase dez anos, eram poucos os alunos negros fora do curso de Pedagogia. E, hoje, você anda pelo Campus, a quantidade de alunos negros é, evidentemente, muito maior, mas ainda é uma universidade maioritariamente branca. (Entrevistado 1. Entrevista realizada em abril de 2019).
}

Nesta direção, de um lado, observamos a seletividade das universidades públicas no país e, das dificuldades de acesso que ainda tangenciam alunos que cursaram o ensino público (educação básica). Por outro, reconhecemos que mesmo inseridos nesse contexto, esta sendo expressiva a transformação ocorrida nos campi das universidades públicas, que possibilitaram por meio de ação afirmativa uma diversificação de perfis estudantis. Desse modo representam um passo importante na democratização do acesso ao ensino superior brasileiro (HERINGER, 2018).

Quando analisamos a base teórica que norteia o projeto do EAP, apreendemos que, por um lado, a base teórica e prática está primordialmente calcada no arcabouço teórico de autores do campo da Educação/Psicologia, em sua grande maioria, sulamericanos e europeus: "Piaget [...], Fernández [...], Paín [...], Pinchona Rivière [...], Bleger [...], Visca [...], Winnicott [...], e Vygotsky [...] Saltini [...], Santiago [...], e Carraher". (PPC/PEDAGOGIA /UFRJ, 2015, p.69). Por outro, muito embora tenhamos uma série de autores no país que discutem o tema das relações étnico-raciais, não os localizamos na proposta do EAP, conteúdo importante "visando à formação de professores para a diversidade étnico-racial" (BRASIL, 2004, p.23).

Apreendemos, portanto, que no PPC do curso de Licenciatura em Pedagogia(FE/UFRJ) - apesar de dar ênfase ao percurso acadêmico do estudante, propondo a aquisição de instrumentos teóricos-conceituais e prático-operacionais com os quais ele terá condições de atuação enquanto pedagogo -, a discussão sobre as questões étnico-raciais ainda parece ser pouco presente. 


\section{O Currículo do Curso de Licenciatura em Pedagogia e a Educação} Antirracista: caminhos em construção

O currículo do curso em Licenciatura em Pedagogia oferece ao licenciado algumas duas áreas: Docência (Educação Infantil, nos anos iniciais do Ensino Fundamental, na Educação de Jovens e Adultos), e Gestão de Processos Educacionais. Pedagogos têm sido inseridos tanto no sistema público como na rede privadas: escolas (rurais, indígenas, quilombolas), empresas, hospitais, sistema prisional, entre outras.

Entendemos que a presença da herança colonial nos currículos educacionais tenta silenciar a História e Cultura Afro-brasileira e Indígena (FERREIRA e SILVA, 2018). Pereira (2019) frisa que "é importante ressaltar que não se pode separar as lutas no âmbito do currículo escolar das contingências e das lutas sociais" (p.130).

Young (2014) acrescenta que "[...] o currículo sempre é: um sistema de relações sociais e de poder com uma história específica; isso está relacionado com a ideia de que o currículo pode ser entendido como "conhecimento dos poderosos" (p.201). Compreendemos que o currículo muitas vezes tem se concentrado "demasiadamente como 'conhecimento dos poderosos' - um sistema concebido para manter desigualdades educacionais". (ibidem, p.201). Os currículos a depender de seus processos podem reproduzir “- ou não- as oportunidades sociais” (ibidem, p.201).

Quais são as formas que o currículo pode assumir? Ao avançarmos nossa análise por meio do PPC das atividades curriculares do Curso de Pedagogia da FE/UFRJ, focalizamos que estas são desenvolvidas a partir de três núcleos estruturantes. O primeiro (Núcleo de estudos básicos), “objetiva promover um estudo acurado e reflexivo do campo da educação, apoiado em uma sólida formação teórica dos saberes que fazem interlocução com esse campo e o constituem" (PPC/PEDAGOGIA/UFRJ, 2015, p.27). O segundo (Núcleo de aprofundamento e diversificação de estudos), "objetiva proporcionar o conhecimento mais acurado de algumas das muitas áreas alcançadas pela Pedagogia" (ibidem, p.28). O terceiro (Núcleo de Estudos Integradores), "abarca as atividades acadêmicas complementares. Através de diferentes possibilidades acadêmicas" (ibidem, p.29-30). Citamos, como exemplo, as 
vivências em atividades de comunicação e expressão cultural (seminários, projetos de iniciação científica, monitorias e extensão).

Com base nessa orientação, o Curso de Pedagogia da FE/UFRJ propõe o aprofundamento de estudos em duas formas: um aprofundamento pleno (implicando na exigência formal de cursar disciplina(s) obrigatória(s) de aprofundamento e, também, realizar prática de ensino e estágio supervisionado específico desse campo); um aprofundamento não pleno (apenas em nível de disciplinas, sem a realização da prática de ensino e estágio supervisionado). (ibidem, 2015).

Assim, "o aprofundamento pleno envolverá a formação para: Docência nas disciplinas pedagógicas do ensino médio (Curso Normal); Docência e gestão de Educação de Jovens e Adultos". (ibidem, p.29). O aprofundamento não pleno envolverá a formação para trabalhar, entre outras com: "Relações étnico-raciais e ensino de História e Cultura Afro-brasileira e Africana[...]. Educação e Etnia e [...] Multiculturalismo e Educação.” (ibidem, p.29).

Durante o levantamento realizado com informações disponíveis na página 5 do curso de Pedagogia da UFRJ, localizamos quarenta e cinco (45) disciplinas obrigatórias e suas respectivas ementas curriculares. Entretanto, das disciplinas obrigatórias ofertadas, nenhuma delas apresentavam em seus títulos, o tema das relações étnicoraciais/(des)colonização.

Quando o foco de atenção foram as disciplinas optativas do curso, localizamos cinquenta e seis (56) disciplinas ofertadas, dentro da matriz curricular do curso de Pedagogia. Porém, no contexto da discussão da educação da relações étnico-raciais, observamos quatro disciplinas cujo os títulos estavam relacionados à temática, isto é, 7,0 \% de disciplinas ofertadas: Educação e Etnia; Intelectuais Negras; Multiculturalismo e Educação; Colonialismo, Educação e Pedagogia da Revolução. Entendemos que essas disciplinas propõem a valorização da cultura e o pensamento afro-brasileiro e indígena, e o conhecimento dos processos do colonialismo, bem como o seu enfrentamento. A argumentação apresentada é baseada na análise das ementas e referências propostas pela matriz curricular do curso de Pedagogia, além dos títulos

${ }^{5}$ https://siga.ufrj.br/sira/temas/zire/frameConsultas.jsp?mainPage=/repositoriocurriculo/8B78EE56-92A4-F799-25C3-oF7EAA7A469A.html 
dessas disciplinas estarem dentro da proposta de nossa investigação (educação das relações étnico-raciais).

A disciplina "Educação e Etnia" objetiva o estudo das teorias e principais conceitos das relações étnico-raciais (etnicidade, raça, racismo). Além, da análise dos principais debates relacionados às causas e evidências das desigualdades educacionais e o contexto étnico-racial na sociedade brasileira: as Políticas de Ação Afirmativa; cultura(s) indígena(s) e cultura(s) afrodescendentes(s) na educação brasileira e os textos das Leis (10.639/2003 e 11.645/20086). A ementa está ancorada por um referencial teórico-metodológico antirracista, onde os autores partem da perspectiva de raça, entendendo-se tal conceito como uma construção social e um conceito analítico fundamental para a compreensão de desigualdades socioestruturais e simbólicas observadas na sociedade brasileira (Hall, 2003).

A segunda disciplina, "Intelectuais Negras", contempla os conhecimentos orais e escritos de mulheres negras. História e experiências diversas dos feminismos negros no Brasil, na América Latina e no continente Africano, apresentando como temas: práticas educativas emancipatórias, relações de gênero e antirracismo, pensamento feminista negro e reeducação das relações étnico-raciais em contextos educacionais, pesquisa ativista e a construção de narrativas na primeira pessoa (escritas de si). Os conceitos de intelectual negra e interseccionalidade se fazem presentes e estão ancorados por um referencial teórico-metodológico de autoras maioritariamente negras alinhadas a luta antirracista e descolonizadora. A disciplina se alinha ao entendimento de que "a luta da comunidade negra e das mulheres exigem da escola o posicionamento e a adoção de práticas pedagógicas que contribuam na superação do racismo e da discriminação racial e de gênero", como assinala Gomes (1996, p.82).

A terceira disciplina, "Multiculturalismo e Educação," propõe eu seu conteúdo programático discussões sobre multiculturalismo (críticas e avanços), quilombolas no Brasil, multi/interculturalidade (debates e possibilidades de atuação), histórias e

\footnotetext{
${ }^{6}$ BRASIL. Lei ${ }^{0}$ 11.645, de 10 de março de 2008. Altera a Lei no 9.394, de 20 de dezembro de 1996, modificada pela Lei no 10.639, de 9 de janeiro de 2003, que estabelece as diretrizes e bases da educação nacional, para incluir no currículo oficial da rede de ensino a obrigatoriedade da temática "História e Cultura Afro-Brasileira e Indígena”. Brasília, DF, 2008.
} 
culturas indígenas, movimentos sociais de base (Movimento Negro), materiais didáticos e racismo no espaço escolar. De modo geral, o referencial teóricometodológico que tangencia a disciplina contempla ainda discussões sobre: a metodologia da História Oral; a Lei $\mathrm{n}^{0}$ 10.639/o3, além de atividades extraclasse visitas pedagógicas aos espaços de memória da população negra no Rio de Janeiro. A base teórica da disciplina parte do entendimento de que o racismo que existe no Brasil "alimenta-se também dos preconceitos e da ignorância em relação às outras culturas e etnias formadoras de nossa sociedade" (PEREIRA, 2013, p. 74).

A quarta disciplina, "Colonialismo, Educação e Pedagogia da Revolução", discute textos que enfocam a luta pela descolonização, em particular, sobre o continente africano (experiências de Alfabetização na Guiné-Bissau), abordando os trabalhos de Amílcar Cabral e Paulo Freire. Desenvolve debates sobre a Pedagogia do Oprimido de Paulo Freire, e das obras de Frantz Fanon (Pele negra, máscaras brancas; Os condenados da terra) que contribuem historicamente para as reflexões sobre uma educação libertadora. Outro enfoque observado na disciplina se refere aos estudos das Epistemologias do Sul, entendidos como expressão "de uma metáfora do sofrimento, da exclusão e do silenciamento de povos e culturas que, ao longo da História, foram dominados pelo capitalismo e colonialismo" (SANTOS e MENESES, 2009, p.183). Quanto o assunto é a sociedade brasileira, há discussões sobre as lutas pela terra empreendidas pelos camponeses (reforma agrária), os negros (recuperação dos quilombos), e os povos indígenas (territórios).

É importante compreendermos a busca de resgatar alguns pressupostos da práxis política de Paulo Freire, isto é, reafirmar a luta por uma sociedade democrática, como apontam os estudos de Boaventura Sousa Santos. Estes autores frisam que a importância da dimensão participativa contribui para a criação de uma nova concepção social e política, capaz de modificar as relações de gênero, de raça e etnias (FETTER et al., 2015).

Ancorados em Freire (2005) nos questionamos "como como poderão os oprimidos, que hospedam o opressor em si, participar da elaboração, como seres duplos, inautênticos, da pedagogia de sua libertação?" Para o autor, "somente na medida em que se descubram "hospedeiros" do opressor poderão contribuir para o 
partejamento de sua pedagogia libertadora" (FREIRE, 2005, p.34). Na visão de Ferreira e Silva (2018, p.101), "a negação e o silenciamento dos saberes das/os estudantes vai se materializando por meio de um currículo colonizado/colonizador que reza que só há uma única cosmovisão válida, a eurocêntrica”. Assim ressaltamos a importância de os estudantes do Curso de Licenciatura em Pedagogia terem disciplinas obrigatórias que discutam o estudo das relações étnico-raciais como orientam as legislações amplamente supracitadas neste texto.

Ressaltamos que mesmo não estando posto de forma explícita nas Leis $n^{0}$ 10.639/2003 e 11.645/2008, entendemos que fica evidenciado de maneira implícita que a referida discussão deve ser de interesse das instituições educacionais de modo geral, o que inclui o Ensino Superior. Assim, ao analisarmos o currículo e a constatação do debate sobre educação das relações étnico-raciais estar restrito ao universo das disciplinas optativas, um dos nossos entrevistados, professor universitário, corrobora: "É isso mesmo, estas disciplinas são eletivas, o aluno de Pedagogia pode passar pelo curso sem cursar nenhuma delas" (Entrevistado 2. Entrevista realizada em abril de 2020).

Nesse sentido, compartilhamos das reflexões de Pereira (2019), quando o autor assinala que:

Da mesma forma que foram desumanizados os africanos escravizados e seus descendentes [...], a partir do século XVI. Essa desumanização se deu e ainda se dá de várias formas, inclusive por meio da violência, que é o apagamento ou a invisibilização das memórias e histórias das populações negras nos currículos e nas escolas. (2019, p.125).

Assim, perguntamos: como o estudante do curso de Licenciatura em Pedagogia poderá se formar para o ensino das relações étnico-raciais? Quem está a se responsabilizar por isto? O aluno? A instituição? Compreendemos que esta atitude não está atribuída ao sujeito em não cursar disciplina(s), mas sim, à instituição, por não ofertar disciplinas obrigatórias sobre o tema das relações étnico-raciais no currículo do curso de Pedagogia. 
Por um lado, observamos disciplinas optativas que abordam uma perspectiva antirracista. Por outro, compreendemos que a ausência7 de disciplinas obrigatórias que abordam as diversas temáticas étnico-raciais, a partir da perspectiva antirracista, só vem a reiterar e visibilizar à necessidade de mudança da matriz curricular atual do curso de Pedagogia. Compartilhamos das reflexões de Gomes (2012) da importância de "formar professores e professoras reflexivos e sobre as culturas negadas e silenciadas nos currículos" (p.102).

\title{
4. A Universidade da Integração Internacional da Lusofonia Afro- Brasileira (UNILAB) e o movimento negro
}

A criação da Universidade da Integração Internacional da Lusofonia AfroBrasileira no ano de 2010 está inserida no contexto de expansão do ensino superior, mas também de conquistas do Movimento Negro na primeira década dos anos 2000. O Movimento Negro esteve como principal agente impulsionador no processo da sua criação, estruturação e implementação, como refletem Sofia Lerche Vieira e Nilma Lino Gomes (2013), essa última uma das principais lideranças responsáveis pela articulação e materialização da UNILAB, em especial do curso de Pedagogia:

\begin{abstract}
O movimento de criação da UNILAB se insere no quarto ciclo expansionista [seriam 4 ciclos de expansão da rede de ensino superior brasileira] [...]. Tal contexto é também marcado pela forte presença dos movimentos sociais no Brasil que cada vez mais incluem o acesso e a permanência à educação superior como uma das suas pautas de lutas. O Brasil vive, a partir dos anos 2000, uma intensa mobilização social em torno dos processos de democratização da educação superior que pressiona as instituições públicas e o Estado e interferem na configuração do quarto ciclo expansionista acima citado (GOMES e VIEIRA, 2013, p.85).
\end{abstract}

Entendemos que a criação da UNILAB é fruto de um processo de redireccionamento das políticas públicas educacionais marcado, em nossa leitura, por

\footnotetext{
${ }^{7}$ Para este estudo focamos apenas no curso de Pedagogia da FE/UFRJ, não esgotando assim, a análise de outros cursos e, ofertas de disciplinas sobre o tema das relações étnico-racial (obrigatórias e/ou optativas), que constam na Instituição.
} 
uma série de demandas de inclusão advinda de diversos movimentos, mas também atravessada pela agenda desenvolvimentista do governo, que articularia crescimento econômico, políticas distributivas e reorientação da política externa.

A criação da UNILAB, portanto, só pode ser entendida em sua complexidade se a considerarmos como um dos elementos chaves na agenda da política externa do Estado brasileiro e que tinha como base a realização de acordos de cooperação, programas e convênios internacionais, que nas palavras de Luís Inácio Lula da Silva, presidente à época da criação da UNILAB, teria como propósito "A cooperação com a África é prioritária para o Brasil [...] Trata-se de relacionamento estratégico” (SILVA AGD, 2019, p. 81).

A criação da UNILAB sinalizava os novos rumos na agenda internacional nas políticas públicas e na educação superior na primeira década dos anos 2000, reunindo a experiência de universidades da integração à interculturalidade (FERREIRA, 2018). Entretanto, entendemos que o projeto político da UNILAB é atravessado por ambiguidades porque se, por um lado, ele é gestado pelo movimento negro a partir de uma articulação que primaria pelo restabelecimento de um projeto político focado no enfrentamento ao racismo, por outro lado, tal projeto político é atravessado pela reordenação da agenda das relações internacionais do governo à época amparados na nova gramática global centrada no paradigma da "interculturalidade funcional":

[...] [nessa lógica] o reconhecimento e respeito pela diversidade cultural tornam-se uma nova estratégia de dominação, que visa não a criação sociedades mais equitativas e igualitárias, mas ao controle de conflitos étnicos e a preservação da estabilidade social, a fim de impulsionar os imperativos econômicos do modelo (neoliberalizado) de acumulação capitalista, agora fazendo" incluir" grupos historicamente excluídos dentro. [...] de fato, essa lógica tem suas raízes no multiculturalismo (neoliberal) Americano como no [...] "interculturalismo europeu". Enquanto o primeiro tem suas raízes na democracia liberal e na liberdade de mercado - o que garante liberdade à diferença e aponta a tolerância da diferença, mas também a sua comercialização, o segundo aponta para um novo humanismo dos diversos: humanizar o neoliberalismo e a globalização [...]" (WALSH, 2012, p. 64) 
Sobre a "interculturalidade funcional" e as novas estratégias do capitalismo global, ao analisarmos o processo de criação da UNILAB, nos chama a atenção que o termo "lusofonia" esteja no nome da Universidade, na oỏj:ö̉ijmedida em que apela à uma comunidade imaginada formada pela integração dos países colonizados baseado em um denominador comum, a saber a língua portuguesa, a língua do colonizador. Estamos de acordo com Miguel Vale de Almeida (2003) quando afirma que:

[...] a língua, que assim deixa de ser vista como resultado material de contingências históricas e passa a ser projecto de identidade comum. Perigosa, esta viragem, pelo que contem de elisão das violências que subjazem à sua implantação histórica, e por remeter para segundo plano os aspectos pragmáticos da cooperação para o desenvolvimento (p. 2).

Como tem sido plausível que uma universidade com um projeto político voltado para a construção de novas abordagens no campo das relações étnico-raciais, mas também na relação com os países africanos, carregue em seu nome a referência à uma identidade política que é transnacional, mas centrada em uma ideia de comunidade lusófona, fruto da dominação (à base de violência) da língua do colonizador? A reprodução da ideia de lusofonia é um dos legados coloniais, posto que só foi possível a manutenção da língua portuguesa pelo processo de negação e invisibilização de toda a variedade linguística dos países colonizados por Portugal.

Entretanto, ao analisarmos o currículo do curso de Pedagogia da UNILAB, veremos que o debate não pode encerrar-se na "lusofonia“. E como bem aponta Ferreira (2018), a reapropriação do termo lusofonia talvez aponte para práticas orientadas pela desobediência epistêmica (idem, p.57). Reconhecemos que é preciso um olhar mais cuidadoso para o emprego da categoria lusofonia no projeto político da UNILAB, pois seria imprudente de nossa parte reduzir as possibilidades estratégicas de usos políticos do termo pelo movimento negro. Em nossa leitura, a noção de “comunidade lusófona" - enquanto utopia e projeto político inseridos no debate feito pelo movimento negro - está envolta em conflitos, contradições e tensões que evidenciam os desafios de um projeto transnacional entre afro-brasileiros e africanos. 
Nesse sentido, tentaremos, ao longo da próxima seção, trazer evidências de como se expressa essa complexidade no currículo do curso de Pedagogia.

\title{
5. Algumas considerações do Projeto Pedagógico e Curricular do curso de Pedagogia na UNILAB
}

O Projeto Pedagógico e curricular da licenciatura em Pedagogia na Unilab é fruto de um intenso processo de debate e articulação entre o corpo docente da UNILAB, militantes do movimento negro e especialistas nas áreas de currículo e antirracismo que compuseram uma comissão para a elaboração do Projeto Pedagógico e curricular do Curso que ficaria pronto em 2014 - $\quad 4$ anos após a criação da UNILAB. Uma das entrevistadas e componente da Comissão que elaborou o Projeto nos conta sobre o intenso processo de negociação e disputas ao longo do trabalho da Comissão:

\begin{abstract}
Então eu chegando na UNILAB [...] encontrei uma grande resistência, porque curriculum é disputa [...]. E aí eu já cheguei sabendo que ia ser pancada, mas eu não sabia que ia ser tanta pancada porque já estava numa [sic] universidade preta, uma universidade que tem uma proposta de cooperação de língua portuguesa em especial África, um monte de estudante africano e que tem essa proposta. Eu disse não vai ter resistência né? [...] eu perguntei: o que já tem de feito [sic] desse projeto? E me apresentaram uma estrutura curricular amparado na pedagogia do Waldorf...pedagogia alemã [...] era interculturalidade nessa vibe da Europa [...] fazendo aquela inclusão daquele jeito [...]? b em no modelo português, bem europeu, de alguns países, não de toda Europa [...] e aí tinha um pedagogo que era do movimento negro de São Paulo [...] Ele era o único preto [na Comissão] do movimento negro, só que ele não estava conseguindo persuadir sozinho, porque ele estava só na comissão para persuadir o grupo pra [sic] tornar aquele projeto mais amparado nas diretrizes da UNILAB [...]" (Entrevistada 1/UNILAB. Entrevista realizada em outubro de 2019)
\end{abstract}

Sobre o trecho anterior gostaríamos de chamar atenção para dois pontos. O primeiro diz respeito ao processo de construção do Projeto Pedagógico e curricular da licenciatura em Pedagogia, onde fica evidente que a construção da matriz curricular é mais que uma questão de "escolhas adequadas", ela própria é forjada no contexto de disputas políticas que refletem, dentre outras questões a indiferença de alguma parte 
da academia brasileira à radicalidade da proposta político pedagógica da UNILAB que nasce como projeto intercultural e de valorização da produção de conhecimento africano e afro-diaspórico mas que no processo de materialização da proposta, encontra a persistência dos "guardiões da supremacia branca" na tentativa de reprodução dos chamados "cânones" europeus.

O segundo ponto diz respeito ao compromisso político em torno de uma causa. A reprodução da crença de um currículo neutro, como chama atenção Michael Apple (1999), tem sido historicamente fonte de contestação e disputas. Nesse sentido, o Projeto Pedagógico vai na contramão dessa "neutralidade":

\begin{abstract}
Infelizmente, passados mais de 10 anos da referida lei [10.639/03], são ainda poucos os reflexos dessa lei nos currículos das universidades brasileiras, as quais, na sua grande maioria, resistem à mudança de sua estrutura curricular, uma vez que exige o aprofundamento de estudos não propiciados aos docentes em serviço, que foram formados por um currículo todo eurocentrado que, de modo assustadoramente hegemônico, coloca a Europa como referência de conhecimento e cultura para o resto do mundo. Sabemos quais são os efeitos devastadores desse currículo eurocentrado, fruto da colonização portuguesa, dos genocídios físicos, filosóficos e epistemológicos dos índios/as e negros/as (PPC Pedagogia, UNILAB, 2014, p. 8).
\end{abstract}

Assim, o Projeto Pedagógico e curricular da licenciatura em Pedagogia tem o objetivo de "[...] formar para o exercício da pedagogia [...] na perspectiva de uma epistemologia da África e de suas diásporas, anti-racista e anticolonial, promotora da efetiva valorização dos saberes científicos e ancestrais" (PPC Pedagogia, UNILAB, 2014, p. 25). A matriz curricular do curso é composta por 60 disciplinas: 44 obrigatórias (ob), 7 eletivas (el) e 7 optativas (op). Após a análise do currículo elaboramos a 3 grandes categorias que atravessam as disciplinas: 1) valorização da cultura e história afro e africana; 2) integração e; 3) descolonização. :öß:Este agrupamento foi baseado na análise dos objetivos das disciplinas, das afinidades argumentativas e referenciais teóricos compartilhados, juntamente com uma análise atenta do texto das Diretrizes Curriculares. Reconhecemos que a sistematização proposta no presente estudo é, obviamente, reducionista (e em alguma medida arbitrária) considerando que alguns aspectos teóricos são partilhados por várias disciplinas que estão em categorias distintas na categorização aqui proposta. 
Acreditamos, no entanto, que a categorização poderá contribuir para situar a complexidade das disputas e tensões no currículo do curso de Pedagogia.

O primeiro grupo que categorizamos é relativo às disciplinas focadas na "valorização da cultura e história afro e africana": entre obrigatórias (13), eletivas (7) e optativas (6), um total de 24 disciplinas $^{8}$. No quadro abaixo, apresentamos as disciplinas:

Quadro 1: Disciplinas focadas na "valorização da cultura e história afro e africana"

\section{Disciplina}

Filosofia da Ancestralidade da Educação (Ob)

Fundamentos Filosóficos e práticos da Capoeira (Ob)

Psicologia Africana da educação (Ob)

Pesquisa em Educação nos países da integração $(\mathrm{Ob})$

História da educação nos países da integração (Ob)

Religiões de matriz africana no Brasil (Ob)

Religiões Tradicionais Africanas $(\mathrm{Ob})$

Fundamentos filosóficos e práticos do samba (Ob)

Ensino de arte e educação africana e da diáspora nos países da integração (Ob)

Ensino da ginga: capoeira, corporeidade e mandinga $(\mathrm{Ob})$

O ensino da etnomatemática $(\mathrm{Ob})$

Ensino da língua portuguesa nos países da integração (Ob)

Ensino das ciências naturais nos países da integração $(\mathrm{Ob})$

Uso pedagógico de mitos e contos africanos e afrobrasileiros (El)

Educação e literatura negro-brasileira (El)

Arte africana e afro-brasileira no ensino fundamental nos países da integração (El)

Arte africana e afro-brasileira na educação infantil nos países da integração (El)

Capoeira, samba e as manifestações africanas e afro-brasileira dos lugares (El)

Tradição oral africana (El)

Cosmovisão Africana e da diáspora (Op)

Corpo, Dança Afro e Educação (Op)

A língua Banta e a sua influência nas manifestações afro-brasileiras (Op)

Aspectos pedagógicos das Brincadeiras e Folguedos de raiz africana no Brasil (Op)

Educação Escolar Quilombola (Op)

\section{Fonte: Elaboração própria.}

${ }^{8}$ Importante ressaltar que há uma disciplina sobre "Educação Escolar Indígena" e a mesma é Optativa. 
A "valorização da cultura e história afro e africana" contempla a gramática empregada na Lei 10.639/o3 e nas Diretrizes Curriculares Nacionais para Educação das Relações Étnico-raciais e para o Ensino de História e Cultura Afrobrasileira e Africana. Nesse sentido, classificamos nessa categoria as disciplinas que fazem menção em suas ementas às contribuições da produção de conhecimento produzida em África e países da diáspora africana.

Observamos nessa categoria que, em algumas disciplinas, a valorização de saberes, histórias e tradições afro ou africanas está atrelada à confrontação do saber ocidental, não apenas visibilizando saberes ancestrais, mas historicizando como o colonialismo silenciou cosmovisões que estavam fora do Ocidente e, nesse sentido, entendemos que esse tipo de abordagem é em si uma proposta descolonizadora. Entretanto as referidas disciplinas dão mais ênfase à gramática presente na Lei 10.639/o3 e por isso classificamos no primeiro grande grupo categórico.

A segunda categoria analítica é “descolonização”. Ao analisar o currículo do Curso de Pedagogia relativo às disciplinas que estão discutindo sobre "colonialismo", “impactos da colonização" e "descolonização”, chegamos a um total de 11 disciplinas, entre obrigatórias (9), eletivas (1) e optativas (1). No quadro abaixo, apresentamos as disciplinas:

Quadro 2: Disciplinas focadas na "descolonização"

\begin{tabular}{|l|}
\hline \multicolumn{1}{|c|}{ Disciplina } \\
\hline Antropologia da educação nos países da integração (Ob) \\
\hline Sociologia da educação nos países da integração (Ob) \\
\hline Organização da educação básica nos países da integração (Ob) \\
\hline Autobiografia e educação (Ob) \\
\hline Didática nos países da integração (Ob) \\
\hline Educação, gênero e sexualidade nos países da integração (Ob) \\
\hline Políticas curriculares e descolonização dos currículos (Ob) \\
\hline Ensino da História nos países da integração (Ob) \\
\hline Estágio em processos educativos não escolares nos países da integração (Ob) \\
\hline Língua Brasileira de Sinais - LIBRAS (El) \\
\hline Pretagogia (Op) \\
\hline
\end{tabular}

Fonte: Elaboração própria 
O entendimento de descolonização presente nas ementas das disciplinas analisadas faz referência à "descolonização do saber" como processo necessário frente ao "racismo e seus desdobramentos". Nesse sentido, as disciplinas propiciam uma aproximação “[...] dos saberes africanos e negro diaspórico em educação uma vez que nossa tradição acadêmica em geral priorizou a edificação do pensamento europeu, tornando necessário o entendimento da nova lógica epistemológica, pedagógica, metodológica necessária ao exercício da docência no referido curso [...] numa perspectiva de descolonização do saber (UNILAB, 2014, p. 41-42).

A terceira categoria analítica diz respeito à noção de "integração". Das disciplinas analisadas, 11 delas (todas são obrigatórias) estão focadas na questão da "integração entre o Brasil e os demais países membros da Comunidade dos Países de Língua Portuguesa- CPLP, [com o objetivo de] promover o desenvolvimento regional, o intercâmbio cultural, científico e educacional" (UNILAB, 2014, p. 4). A seguir, as disciplinas:

Quadro 3: Disciplinas focadas na "integração”

\section{Disciplina}

Política educacional nos países da integração (Ob)

Fundamentos da gestão educacional nos países da integração (Ob)

Alfabetização e letramento nos países da integração (Ob)

Educação infantil nos países da integração $(\mathrm{Ob})$

Educação ambiental nos países da integração $(\mathrm{Ob})$

Ensino da geografia nos países da integração (Ob)

Ensino da EJA nos países da integração (Ob)

Estágio na educação infantil nos países da integração $(\mathrm{Ob})$

Estágio em gestão educacional nos países da integração $(\mathrm{Ob})$

Estágio em Educação de Jovens e adultos nos países da integração (Ob)

Estágio nas séries iniciais do ensino fundamental nos países da integração (Ob)

\section{Fonte: Elaboração própria}

Se, por um lado, a proposta de estreitamento dos laços com os países africanos pode ter relação com as novas diretrizes políticas das relações internacionais do governo do Partidos dos Trabalhadores, por outro, a análise das ementas aponta para a possibilidade de uso estratégico dessa integração pelo movimento negro, por sua vez baseada no fortalecimento das relações políticas com aqueles países, pois "[...] a realidade dos efeitos alienantes da colonização europeia sobre os currículos é problema 
que afeta também sobremaneira os países africanos, notadamente os da integração lusófona” (UNILAB, 2014, p. 9).

Para finalizar, em nossa leitura, o ensino da História e Cultura Africana e AfroBrasileira no curso de pedagogia da UNILAB não tem sido um componente marginal em relação ao currículo, isto é, não se limita à oferta pontual de disciplinas, pelo contrário, a estruturação do currículo está voltado não somente para o cumprimento da lei que obriga o ensino História e Cultura Africana e Afro-Brasileira, mas para a desconstrução da canonicidade da epistemologia eurocentrada, onde a prática curricular reflete também a busca pela “descolonização das mentes”, parafraseando uma de nossas entrevistadas (Entrevistada 1/UNILAB. Entrevista realizada em outubro de 2019).

\section{CONSIDERAÇÕES FINAIS}

Gostaríamos de pontuar algumas reflexões gerais acerca da análise do currículo nos cursos de pedagogia da UFRJ e UNILAB. O primeiro ponto diz respeito ao contexto histórico de criação das duas universidades e, portanto, dos cursos de pedagogia em ambas as instituições. Enquanto a criação da UFRJ está inserida no contexto de consolidação do Brasil republicano, marcado por grandes mudanças acerca do papel da educação para o "desenvolvimento e progresso da nação", a UNILAB nasce no século XXI, fruto da pressão do movimento negro e incorporada ao projeto desenvolvimentista de um governo progressista que tinha na agenda de governo a questão da expansão do ensino superior público, assim como uma agenda externa voltada para estreitamento das relações com países africanos.

As especificidades dos contextos políticos e econômicos sob os quais emergem as duas universidades nos ajudam a compreender as diferenças (e divergências) dos projetos políticos e pedagógicos de cada uma delas: enquanto o projeto político da primeira persiste na reprodução do modelo escolar europeu para a realidade brasileira tendo como "maior desafio a democratização da universidade" (UFRJ, 2019, p.3), a segunda instituição nasce a partir de um projeto políticopedagógico voltada para a desconstrução do modelo epistemológico europeu de 
universidade e de pedagogia, buscando construir um referencial teórico, metodológico e epistêmico de formação de professores de base afrobrasileira e africana.

O segundo ponto diz respeito aos referenciais bibliográficos presentes nas ementas das disciplinas analisadas nos dois cursos e a (im)permeabilidade antirracista nas propostas pedagógicas curriculares. Se por um lado, é possível observarmos que o projeto político do curso de pedagogia da UFRJ ainda parece resistir ao diálogo com as diretrizes para a educação das relações étnico-raciais e do ensino da história afrobrasileira e africana, o currículo do curso, faz uma tentativa de construção de novas discussões que privilegiam as DCN como observamos nas disciplinas optativas do Curso apresentas nas páginas anteriores. Nesse sentido, observamos um caráter "híbrido" nos referenciais, onde encontramos a presença de intelectuais afrobrasileiro(a)s e brancos (incluindo europeus).

No caso da proposta pedagógica curricular da UNILAB, notamos que há uma predominância de uma bibliografia que dialoga com a produção de conhecimento antirracista de autores e autoras negras de África e da diáspora brasileira. A partir das referências bibliográficas presente nas ementas, é possível afirmar que para além da busca por representatividade, o currículo reflete o esforço de construção de uma cosmovisão africana e diaspórica que oriente as práticas pedagógicas dos estudantes.

O terceiro ponto é sobre o entendimento da importância do debate sobre antirracismo refletido nos projetos pedagógicos dos cursos. Enquanto a primeira universidade tem como objetivo geral em seu curso de Pedagogia formar pedagogos aptos para conhecer, analisar e discutir o campo teórico-investigativo da educação (processos ensino-aprendizagem, trabalho pedagógico) para intervir nas diversificadas situações apresentadas pela realidade educacional brasileira, a segunda universidade, objetiva a produção e disseminação de conhecimento, na perspectiva de uma epistemologia antirracista e anticolonial na formação dos pedagogos.

Entendemos que para os futuros pedagogos da primeira universidade estarem "preparados para intervir nas diversificadas situações apresentadas pela realidade educacional brasileira", como sugere o plano político-pedagógico (PPC/PEDAGOGIA//UFRJ, 2015, p.12), o debate sobre antirracismo não deveria ser incluído apenas em disciplinas optativas, visando atender as normativas e leis federais, 
desconsiderando uma educação antirracista de forma generalizada e estrutural na matriz curricular e nesse sentido ressaltamos a importância da implementação de disciplinas obrigatórias sobre o tema das relações-étnico raciais.

O quarto ponto se refere ao entendimento de antirracismo, colonização/colonialismo nos projetos pedagógicos. No que tange a primeira universidade, notamos que o termo "colonialismo" é mencionado uma única vez no PPC, em particular, no contexto de uma disciplina optativa "Colonialismo, Educação e a Pedagogia da Revolução”. Nesse sentido, observamos que a disciplina busca dar visibilidade a outras formas de saber que são deliberadamente silenciadas: saberes dos povos indígenas, quilombolas, de povos de África. Notamos que o currículo se apresenta como um modelo eurocentrado com raras exceções, que são as quatro disciplinas optativas, já evidenciadas neste texto.

A segunda universidade se apresenta com uma matriz curricular comprometida em seu processo de formação para o exercício da Pedagogia com um perspectiva de um currículo decolonial e afrocentrado. Isto é, propõe que seus estudantes de Pedagogia sejam produtores "de conhecimentos, na perspectiva de uma epistemologia da África e de suas Diásporas, antirracismo e anticolonial e promotor da efetiva valorização dos saberes científicos e ancestrais, com ênfase nos países da integração da UNILAB” (UNILAB, 2013, p. 62).

A análise dos projetos políticos dos cursos de pedagogia das duas universidades e dos seus currículos revelam as disputas e ambiguidades existentes na construção da educação antirracista no ensino superior público brasileiro. Entendemos por educação antirracista nos cursos de pedagogia um conjunto de práticas pedagógicas e curriculares que reconheçam a importância da produção de conhecimento afrobrasileiro africano assim como problematize os referenciais eurocentrados que naturalizam a reprodução do racismo na educação.

O currículo expressa as diversas tensões, contradições e interesses de vários grupos que estão dentro e fora da universidade. Nesse sentido, o debate que o movimento negro no Brasil tem realizado em relação ao papel que a universidade tem desempenhado historicamente na (re)produção do racismo, parece cada vez mais atual 
e urgente que ela não esteja apenas presente em disciplinas isoladas nas salas de aula do ensino superior, mas se converta de fato em um projeto de educação antirracista.

\section{Referências}

ALMEIDA, Miguel Vale. Prefácio Ao livro Versões. Mundos (D)Escritos em Português. Associação para a Cooperação, Intercâmbio e Cultura. Lisboa, 2003. Disponível em: http://miguelvaledealmeida.net/wpcontent/uploads/2008/06/prefacio-versoes.pdf. Acesso em 9 Jul 2020.

ANDRADE, Michely Peres. Lélia Gonzalez e o papel da educação para o feminismo. Revista Interritórios, Caruaru, v.4, n.6, p.76-92,2018.

APPLE, Michael W. Ideologia e Currículo. São Paulo: Brasiliense, 1982.

Conhecimento oficial - a educação democrática numa era conservadora. Petrópolis:

Editora Vozes, 1999.

CARVALHO, Isabela Bastos de; CASTRO, Alexandre de Carvalho. CARVALHO, I. B.; CASTRO, A. C. Currículo, Racismo e o Ensino de Língua Portuguesa: as Relações Étnico-Raciais na Educação e na Sociedade. Educ. Soc., Campinas, v. 38, n. 138, p. 133-151, 2017.

CHAGAS, Waldeci Ferreira. História e Cultura Afro-Brasileira e Africana na Educação Básica da Paraíba. Educ. Real., Porto Alegre, v. 42, n. 1, p. 79-98, 2017.

COELHO, Mauro Cezar; COELHO, Wilma de Nazaré Baía. As Licenciaturas em História e a Lei 10.693/03: percursos de formação para o trato com a diferença? Educ. rev., Belo Horizonte, v. 34, p.1-39, 2018.

FETTER, Shirlei Alexandra; LEMES, Raquel Karpinski; ZITKOSKI, Jaime José. Democracia e Sociedade: na visão de Boaventura de Sousa Santos e Paulo Freire. Disponível em: < https://www2.faccat.br/portal/sites/default/files/fetter_lemes_zitkoski. Acesso em 5 nov.2020. 
FERREIRA, Verônica Moraes. Tensões em torno da questão étnico-racial no currículo de cursos de pedagogia. São Paulo, 2018, 225 f. Tese (Doutorado) - Programa de Pósgraduação em Educação da Faculdade de Educação da Universidade de São Paulo, São Paulo.

FERREIRA, Michele Guerreiro. Educação das relações étnico-raciais e prática curricular de enfrentamento do racismo na UNILAB. Tese de doutorado apresentado ao Programa de Pós-graduação em Educação, Universidade Federal de Pernambuco, 2018, 275 f.

FERREIRA, Michele Guerreiro; SILVA, Jansen Felipe da. Confluências entre a Pedagogia Decolonial e a Educação das Relações Étnico-Raciais: Elementos de uma Práxis Curricular outra a partir das contribuições de Frantz Fanon e Paulo Freire. In: GARCIA, M. F.; SILVA, J.N. (Org.). Africanidades, Afrobrasilidades e processo (des) colonizador: contribuições à implementação da Lei 10.639/03. João Pessoa: Editora UFPB, 2018, p.75-114.

FREIRE, Paulo. Pedagogia do Oprimido. Rio de Janeiro: Paz e Terra, 2005.

GOMES, Nilma Lino; VIEIRA, Sofia Lerche. Construindo uma ponte Brasil-África: a Universidade da Integração Internacional da Lusofonia Luso- Afrobrasileira (UNILAB). Rev. Lusófona de Educação, Lisboa, n. 24, p. 75-88, 2013.

GOMES, Nilma Lino. Relações étnico-raciais, Educação e Descolonização dos Currículos. Currículo sem Fronteiras, v.12, n.1, p. 98-109, 2012.

GOMES, Nilma Lino. Educação, raça e gênero: relações imersas na alteridade. Cadernos Pagu, n. 6/7, p. 67-82, 1996.

HALL, Stuart. Da Diáspora: identidade e mediações culturais. Belo Horizonte: Ed. UFMG, 2003.

HERINGER, Rosana. Democratização da educação superior no Brasil: das metas de inclusão ao sucesso acadêmico. Rev. bras. orientac. prof, Florianópolis, v. 19, n. 1, p. 7-17, jun. 2018. 
MAESO, Silvia Rodríguez. O Estado de negação e o presente-futuro do antirracismo: Discursos oficiais sobre racismo, 'multirracialidade' e pobreza em Portugal (19852016). Rev. Direito Práx., Rio de Janeiro, v. 10, n. 3, p. 2033-2067, 2019.

PASSOS, Joana Célia dos; SANTOS, Carina Santiago dos Passos. A Educação das relações étnico-raciais na EJA: entre as potencialidades e os desafios da prática pedagógica. Educ. rev., Belo Horizonte, v. 34, e192251, 2018.

PEREIRA, Amilcar Araujo. Memória, democracia e educação: reflexões sobre diversidade étnica e história oral. Revista História Oral da ABHO, Rio de janeiro, v.16, n.1, p.69-84,2013.

PEREIRA, Amilcar Araujo. Black Lives Matter nos Currículos? Imprensa Negra e Antirracismo em Perspectiva Transnacional. Cad. Pesqui., São Paulo, v. 49, n. 172, p. 122-143, 2019.

QUIJANO, Aníbal. Colonialidade do poder, Eurocentrismo e América Latina. Buenos Aires: CLACSO, 2005.p,227-278.

REGIS, Kátia; BASILIO, Guilherme. Currículo e Relações Étnico-Raciais: o Estado da Arte. Educ. rev., Curitiba, v. 34, n. 69, p. 33-6o, 2018.

SANTOS, Boaventura de Sousa; MENESES, Maria Paula. (orgs.). Epistemologias do Sul. Coimbra: Almedina, 2009.

SILVA, Antonio Gislailson Delfino. A política externa do Governo Lula com a África Lusófona: dimensão política, cooperativa, educacional e econômica. In: Revista do Instituto de Ciências Humanas, vol. 15, n⿳0 22, 2019.

UNILAB é pagamento de dívida histórica com a África, diz Lula. Portal Terra, São Paulo, 26 jul. 2010. Disponível em:

https://www.terra.com.br/noticias/educacao/unilab-e-pagamento-de-dividahistorica-com-a-africa-dizlula,2e19ec8d7cbea310VgnCLD2000oobbcceboaRCRD.html. Acesso em: 8 mai. 2020. 
UNIVERSIDADE DA INTEGRAÇÃO INTERNACIONAL DA LUSOFONIA AFROBRASILEIRA (UNILAB). Diretrizes Gerais da UNILAB, 2010. Disponível em: http://pdi.unilab.edu.br/wpcontent/uploads/2013/08/Diretrizes_Gerais_UNILAB.pdf. Acesso em 10 mar 2020.

UNIVERSIDADE DA INTEGRAÇÃO INTERNACIONAL DA LUSOFONIA AFROBRASILEIRA (UNILAB). Projeto Pedagógico Curricular Licenciatura em Pedagogia, 2014. Disponível em:http://www.unilab.edu.br/wp-content/uploads/2016/o1/PPCPEDAGOGIA-2014.pdf Acesso em 10 setembro de 2019.

UNIVERSIDADE FEDERAL DO RIO DE JANEIRO. UFRJ autônoma, crítica e democrática. Balanço de Gestão. Rio de Janeiro, 2019. Disponível em < https://ufrj.br/sites/default/files/documentos/2019/o6/balanco-de-gestaoufrj.pdf $>$.Acesso em 17 jul.2020.

UNIVERSIDADE FEDERAL DO RIO DE JANEIRO. Projeto Pedagógico de Curso Curso de Licenciatura em Pedagogia. Rio de Janeiro, 2015. Disponível em < http://www.educacao.ufrj.br/wp-content/uploads/2019/o8/PPC-atualizado-20142015.pdf $>$. Acesso em 20 fev.2020.

VAN DIJK, Teun Adrianus. Principles of Critical Discourse Analysis. Discourse \& Society, v.4, n.2, p. 249-283, 1993.

WALSH, C. Critical and (de) colonial interculturality. Ensayos from Abya Yala, Quito, Abya-Yala / Scientific Institute of Indigenous Cultures, 2012.

YOUNG, Michael. Teoria do currículo: o que é e por que é importante. Cad. Pesqui., São Paulo, v. 44, n. 151, p. 190-202,2014.

\section{Sobre os autores:}

Danielle Pereira de Araújo: Doutora em Ciência Política pela Universidade Estadual de Campinas São Paulo (Brasil). Atualmente é investigadora em pósdoutoramento no Centro de Estudos Sociais (Projeto 725402 - POLITICS - ERC-2016- 
COG). É integrante do Núcleo Antirracista de Coimbra e da Coletiva Corpos Insubmissos. Email: daniellearaujo8888@gmail.com

Marcos Antonio Batista da Silva: Doutor em Psicologia Social pela PUC-SP. Investigador em pós-doutoramento no Centro de Estudos Sociais, Universidade de Coimbra (Projeto 725402 - POLITICS - ERC-2016-COG). Professor colaborador do Programa de Pós-Graduação em Educação Escolar na Faculdade de Ciências e Letras (Unesp)-Araraquara.E-mail: marcossilva@ces.uc.pt 